\title{
Statin Use and Osteoarthritis
}

\author{
Umesh T. Kadam, MB, ChB, MRCGP, MPhil, MSc, PhD, FFPH' , Milisa Blagojevic, BSc, MSc, PhD², \\ and John Belcher, BSc, MPhil, PhD ${ }^{3}$
}

${ }^{7}$ Health Services Research Unit, Keele University, Staffordshire, England, UK; ${ }^{2}$ Arthritis Research UK Primary Care Centre, Keele University, Staffordshire, UK; ${ }^{3}$ Department of Mathematics, Keele University, Staffordshire, UK.

J Gen Intern Med 28(9): 1135

DOI: $10.1007 / \mathrm{s} 11606-013-2478-1$

(c) Society of General Internal Medicine 2013

$\mathrm{T}$ he Authors' Reply_-We thank Dr Rashid for highlighting the importance our findings, ${ }^{1}$ as well as the wider generic implications that relate to common treatment pathways and shared mechanisms in the pathogenesis of chronic diseases such as cardiovascular disease and osteoarthritis.

There has been much interest in the pleiotropic effects of statins, and a number of studies have provided supportive as well as contrarian evidence. For example, in a large database study, Smeeth et al. showed that for a range of outcomes, statins use was not associated with benefit. ${ }^{2}$ However, this study did not include osteoarthritis as an outcome, and the statin measure was defined simply as use or non-use, without consideration of potential dose threshold effects. The implication of these results is not that potential pleiotropic effects do or do not occur for a specific drug class such as statins, but whether they are placed within well-constructed and impartial hypotheses using the current evidence base on mechanisms.

The broader and generic implications of this study on shared mechanisms are scientifically exciting, and again require a measured and clear approach. Broadly, the mechanisms for osteoarthritis in our paper focused into either anti-inflammatory properties of statins or a modification of the metabolic process. We agree that there is evidence for an inflammatory component to osteoarthritic joints, whilst the evidence on whether this can be mediated systemically in generalised osteoarthritis remains to be established clearly. ${ }^{3}$ Combined with findings from a Swedish cohort, ${ }^{4}$ our article suggests that there is a clear need for further research into the shared mechanisms in cardiovascular disease and osteoarthritis, as well as trials on the feasibility of using statins in osteoarthritis. We should also add that osteoarthritis is a 'complex' chronic disease that encompasses broader determinants, such as psychological status ${ }^{5}$ and mechanical factors, which means that both drug and non-drug therapeutic approaches and mechanisms may need to be delineated clearly.

Corresponding Author: Umesh T. Kadam, MB, ChB, MRCGP, MPhil, MSc, PhD, FFPH; Health Services Research Unit, Keele University, Staffordshire, England ST5 5NB, UK $\left(e^{-}\right.$ mail: u.kadam@keele.ac.uk).

\section{REFERENCES}

1. Kadam UT, Blagojevic M, Belcher J. Statin use and clinical osteoarthritis in the general population: a longitudinal study. J Gen Intern Med. 2013. doi:10.1007/s11606-013-2382-8

2. Smeeth L, Douglas I, Hall AJ, Hubbard R, Evans S. Effect of statins on a wide range of health outcomes: a cohort study validated by comparison with randomized trials. Br J Clin Pharmacol. 2009;67(1):99-109.

3. Chevalier X, Eymard F, Richette P. Biologic agents in osteoarthritis: hopes and disappointments. Nat Rev Rheumatol. 2013. doi:10.1038/ nrrheum.2013.44.

4. Kadam UT, Holmberg A, Blagojevic M, Nilsson PM, Åkesson K. Risk factors for cardiovascular disease and future osteoarthritis-related arthroplasty: a population-based cohort study in men and women from Malmö, Sweden. Scan J Rheumatol. 2011;40(6):478-485.

5. Lin EH, Katon W, Von Korff M, Tang L, Williams JW Jr, Kroenke K, et al. Effect of improving depression care on pain and functional outcomes among older adults with arthritis: a randomized controlled trial. JAMA. 2003;290(18):2428-2429. 